\title{
ROUSSEAU, CORPO E INFÂNCIA: A EDUCAÇÃO DO CORPO INFANTIL COMO PROJETO DE FORMAÇÃO HUMANA
}

Vilson Aparecido da Mata ${ }^{1}$

\begin{abstract}
Resumo
O texto procura apresentar reflexões a respeito da educação do corpo e da infância a partir dos textos de JeanJacques Rousseau. As questões relativas ao corpo ocupam lugar de destaque no autor do Contrato Social, uma vez que ele concebe a educação como instrumento privilegiado para a transformação da sociedade. Pela educação, Rousseau (1999c; 1995) quer formar o indivíduo novo para uma sociedade nova. Partindo das duas categorias de desigualdades entre os seres humanos (desigualdade natural e desigualdade moral e política), Rousseau argumenta ser o caminho trilhado pela civilização o responsável pela degradação dos indivíduos, impactando o corpo, que se tornou fraco e fragilizado pela falta de interação com a natureza e pelas comodidades da vida civilizada. Resgatar o corpo como expressão essencial da existência humana é, para Rousseau (1995), regenerar a própria espécie humana. Para isso, é preciso começar a educar desde a mais tenra infância e, a partir dessa ideia, Rousseau (1995) vai também conceituar a infância de uma forma muito diferente daqueles que o antecederam. Embora distante no tempo, as obras de Rousseau permanecem importantes pontos de apoio para a reflexão a respeito da educação do corpo, posto que tenha sido na sua época que as reivindicações por uma educação pública tenham ganhado força na medida em que a formação do cidadão livre também ganhava destaque.
\end{abstract}

Palavras Chave: Educação; Educação do Corpo; Rousseau; Infância.

\section{ROUSSEAU, BODY AND CHILDHOOD: THE EDUCATION OF CHILDREN'S BODY AS A HUMAN EDUCATION PROJECT}

\begin{abstract}
The text intends to introduce reflections about the education of the body and the childhood from the texts of JeanJacques Rousseau. The issues related to the body have an outstanding position to the author of Social Contract, once he considers education a privileged instrument to the transformation of society. Through education, Rousseau (1999c; 1995) intends to build a new individual to a new society. From the two categories of inequalities among human beings (natural inequality and political and moral inequality), Rousseau argues that the path mapped out by civilization is responsible for the degradation of individuals, impacting the body, which became weak and fragile by the lack of interaction with nature and by the conveniences of civilized life. Rescuing the body as an essential expression of human existence is, to Rousseau (1995), to regenerate the human species itself . In this regard, it is necessary to educate from the earliest childhood and, from this ideia, Rousseau (1995) gives infancy a concept that is very different from the ones given by his predecessors. Although distant in time, the works of Rousseau remain as important supporting points to the reflection about the education of the body, once it was in his time that the requests for a public education gained strength as far as the formation of the free citizen also gained more prominence.
\end{abstract}

Keywords: Education; Education of the Body; Rousseau; Childhood.

1 É graduado em Educação Física pela Universidade Estadual de Maringá (1991), mestre em Educação pela Universidade Estadual de Maringá - área de concentração em Fundamentos da Educação (2000) e doutor em Educação pela Universidade Federal do Ceará - área de concentração em Filosofia e Sociologia da Educação (2014). Atualmente é docente do curso de Licenciatura em Educação Física do Setor Litoral da Universidade Federal do Paraná (UFPR). E-mail: vdamata@hotmail.com. http://orcid.org/0000-0002-2823-6678 


\section{Introdução}

O texto aqui apresentado representa um estudo sobre a educação do corpo na infância expresso na obra de Jean-Jacques Rousseau (1712-1778). Esse pensador ocupa lugar destacado nas discussões acerca da educação e também naquelas que se referem à educação do corpo. Embora haja estudos a respeito da permanência de Rousseau na educação, as questões relativas à educação do corpo permanecem ora inexistentes, ora secundarizadas e, por isso, este texto pretende resgatar esse elemento na obra do genebrino. Em um estudo histórico, entretanto, o objeto da análise não surge imediatamente diante dos olhos, é preciso que se entenda os fatores que permeiam os caminhos trilhados pelo autor. Nesse sentido, Rousseau é um homem de seu tempo, uma vez que ao tratar das questões candentes do século XVIII, abordou-as de modo tão universal que, ainda nos dias atuais, permanecem relevantes.

Rousseau é um filósofo cujos apontamentos a respeito da política e o desenvolvimento da civilização refletem na própria estruturação e crítica da organização política contemporânea. Foi um pensador político sagaz e atento, protestando contra os privilégios dos ricos (fossem eles aristocratas ou burgueses) que acentuavam as desigualdades sociais; defendendo o princípio segundo o qual a grandeza de um país reside em seu povo. Foi o filósofo da liberdade plena e combateu as antigas concepções religiosas, postulando uma organização social na qual as desigualdades fossem superadas.

O genebrino assumiu os princípios burgueses segundo os quais as amarras feudais do antigo regime obliteravam a liberdade dos indivíduos, acentuavam as desigualdades e aprofundavam os vícios, privilégios e a maldade. Mas não permaneceu cativo desses princípios. Queria a mudança social e não cria no desenvolvimento de um Estado racional como solução para a sociedade. Rousseau queria uma nova civilização fundada em um contrato social que preservasse os bons instintos humanos.

Iluminista, discordou de seus contemporâneos a respeito das contribuições das ciências e das artes para o progresso humano (ROUSSEAU, 1999b); jusnaturalista, criticou o pensamento comum de sua época a respeito do "estado de natureza" (ROUSSEAU, 1999a); contratualista, considerava que a liberdade individual deveria ser balizada, por um lado, pela vontade e, por outro, pela comunidade e teria como pressuposto uma igualdade moral e política estabelecida pelo contrato social (ROUSSEAU, 1999c); pedagogo, cria na educação como instrumento privilegiado para a formação de um indivíduo capaz de transformar a sociedade (ROUSSEAU, 1995). Por conta disso, sua obra é clássica para a filosofia, bem como para a 
educação e suas considerações sobre esse tema tornaram-se marcos de mudança e de orientação aos tempos futuros.

Em sua obra, formação e política, universal e particular, natureza e civilização estão entrelaçados, o que leva Rousseau a pensar o desenvolvimento do ser humano de um modo muito diferente da tradição educacional de seu tempo. Sintetizando um movimento que já ganhava força no século XVIII, encaminha um entendimento sobre a infância e sobre os cuidados que essa educação dever ter com o corpo significativamente marcante: doravante, a infância não é mais um período incômodo e inútil, marcado pela fraqueza e digna de humilhação (ARIÈS, 1981), mas um período próprio, relevante e merecedor de especial atenção. Para Rousseau, a formação do cidadão começa na mais tenra idade.

Nesse sentido, é preciso salientar que ideias e ideais educacionais não podem ser dissociados de seu tempo histórico. Em diferentes momentos há diferentes formas de se conceber a educação e também a educação do corpo, posto que a ele sejam direcionadas, intencionalmente ou não, especificamente ou não, todos os processos educacionais. Analisar a educação do corpo em Rousseau, então, demanda que não se restrinja o estudo a uma leitura pura e simples de suas considerações sobre o tema, mas antes, é preciso adentrar a época dos escritos. Isso no intuito de descobrir os elementos duradouros de seu pensamento, os que se modificaram e outros ainda que eventualmente já estejam superados. Essa busca pela inserção do autor em sua época torna possível identificar importantes aspectos sobre o contexto, as lutas, as diferenças e semelhanças em relação aos seus contemporâneos, bem como suas contribuições ao nosso tempo.

Procurando apresentar a educação do corpo como parte fundamental da formação do cidadão idealizada por Rousseau, a primeira parte do texto discorre sobre o mundo no qual Rousseau viveu e produziu; na sequência, a questão da desigualdade e dos descaminhos da civilização e, após, o modo como o genebrino concebe a educação na infância e o lugar ocupado pelo corpo.

\section{Sobre como Rousseau vê o Mundo}

Rousseau viveu e produziu no "século das luzes", assim chamado por ter sido palco de lutas sociais, da ascensão da burguesia e da emergência do Iluminismo. Embora predominantemente agrário, com a imensa maioria da população europeia vivendo em áreas rurais (HOBSBAWN, 2011), o progresso econômico, apoiado no desenvolvimento do comércio 
e no avanço científico, torna esse período efervescente de transformações sociais que, menos de um século depois, terá modificado drasticamente a paisagem do mundo:

A convicção no progresso do conhecimento humano, na racionalidade, na riqueza e no controle sobre a natureza - de que estava profundamente imbuído o século XVIII - derivou sua força primordialmente do evidente progresso da produção, do comércio e da racionalidade econômica e científica que se acreditava estará associada a ambos (HOBSBAWN, 2011, p. 47).

Essas transformações expressam o esgotamento das instituições do antigo regime, que não respondem mais às demandas sociais, que se defrontam com a emergência do comércio, da indústria, da mecanização progressiva da produção e com o surgimento de ideais que impunham um novo tipo de indivíduo e uma outra forma de organização política. As velhas instituições tornaram-se óbices às esperanças de equalização social, justiça, retidão moral.

Emerge, assim, uma nova forma de sociedade sustentada pelo avanço científico, que proporcionou a invenção da máquina de fiar, do tear mecânico e, finalmente, o início da Revolução Industrial, bem como a Revolução Francesa, que dá ao mundo o vocabulário da política liberal e da radical democracia (HOBSBAWN, 2011). Como expressão ideal das transformações materiais, o Iluminismo reivindica a razão e o saber como instrumentos de conhecimento da realidade, contrapondo-se ao obscurantismo medieval, dominado pela ignorância e pela superstição. Tem decisiva influência sobre o desenvolvimento da sociedade, por exemplo, quando critica o absolutismo e reivindica um Estado racional, resultando em uma série de proposições que contribuem para a fundação do Estado moderno.

Os iluministas assumem uma posição política que coincide com as camadas mais progressistas da sociedade (particularmente, a burguesia): os anseios pelas liberdades individuais; a proposição de um Estado racional; o direcionamento pela equalização social e a confiança no conhecimento científico (HOBSBAWN, 2011). Entre os iluministas, Rousseau é uma voz dissonante. Ele se desviou da questão da forma do Estado, da confiança cega na razão e na ciência para a equalização social e mostrou-se muito pessimista em relação aos caminhos trilhados pela civilização (BOTO, 2011). Lamenta ainda o genebrino que o desenvolvimento das luzes não tenha acrescentado nada à felicidade humana (PAIVA, 2016). Ao contrário, trouxe a decadência e deu vazão aos instintos mais depravados, como o amor pelo luxo, a vaidade, a inveja (PAIVA, 2016). Engels sintetizou bem o modo como Rousseau via seu mundo: "cada novo progresso da civilização é, ao mesmo tempo, um novo progresso da desigualdade" (ENGELS, 2015, p. 169). 
Considerando as mudanças que tiveram como palco o século XVIII, é preciso voltar o olhar para o fato de que elas implicam transformações também nos indivíduos. É assim em relação à própria concepção de infância, como com a de educação. O futuro da criança passa a ser reconhecido como importante, digno de atenção, ganhando cada vez mais espaço na vida daquelas famílias cuja posição social e inclinação política demandava que os filhos não fossem somente herdeiros de um patrimônio, mas também de um legado moral, filosófico e político. "A família deixou de ser apenas uma instituição de direito privado para a transmissão dos bens e do nome, e assumiu uma função moral e espiritual, passando a formar os corpos e as almas" (ARIÈS, 1981, p. 279).

Entre as questões importantes para a educação, está a condenação dos castigos corporais, tão comuns no medievo. Também inclui a aprendizagem dos gestos adequados ao cidadão, o conhecimento do corpo e o controle da conduta a fim de melhor se movimentar nos círculos sociais. Há um direcionamento da educação para a infância: sua formação é uma necessidade à classe mais progressista, que vê na ciência e na retomada da tradição clássica um caminho para a constituição da nova sociedade burguesa. De período inútil e identificado com a fraqueza (ARIÈS, 1981), torna-se o momento mais propício para a formação dos indivíduos novos. "Surgiu a ideia de que a infância não era uma idade servil e não merecia ser metodicamente humilhada" (ARIÈS, 1981, p. 181).

Evidentemente, a "ideia" de que a infância seja mais do que meramente uma idade servil não "surgiu" pronta na cabeça das pessoas no século XVIII. Há mudanças sociais importantes que indicam esse caminho. Rousseau ocupa um lugar destacado nesse processo, posto que tenha, em seus escritos, apresentado uma concepção educacional e de infância decorrente de uma concepção política crítica à sociedade existente e que buscava, pela educação, desde a infância, formar indivíduos novos para uma nova sociedade. É preciso adentrar categorias centrais de Rousseau para encaminhar uma reflexão sobre a sua época e porque ele nega o otimismo em relação à razão existente, além de propor outra forma para a organização política, para a educação e para o modo como o corpo deveria ser educado.

\section{Desigualdade, Perfectibilidade e liberdade}

Rousseau (1999a) concebe dois tipos de desigualdades entre os seres humanos: A desigualdade natural e a desigualdade moral ou política. O primeiro tipo de desigualdade diz respeito às capacidades corporais (habilidades, força, destreza, etc), à idade, saúde e às 
"qualidades do espírito e da alma" (ROUSSEAU, 1999a, p. 51), como a coragem, a vontade, etc. As desigualdades naturais não podem ser evitadas, ou, não há possibilidade de controle sobre elas. São formas de existir dos indivíduos que, naturalmente, são mais altos ou mais baixos, com conformação física mais vigorosa ou apoucada, uns são mais expeditos, outros menos (ROUSSEAU, 1999a). Contudo, essas desigualdades não se constituem em impedimentos para o desenvolvimento humano, pois caracterizam os indivíduos em seu estado natural, no qual não são indicadoras de vícios ou de crueldade, mas elementos complementares à preservação da vida.

O estado de natureza é tanto hipotético quanto histórico, posto que se refira ao ser humano em um período anterior à civilização. Para o genebrino, a natureza possui uma ordem intrínseca, que consiste no equilíbrio entre a necessidade de autopreservação e aquilo que pode ser retirado dela a fim de que se cumpra a existência dos seres humanos (ROUSSEAU, 1999a; 1995). O indivíduo, então, em estado de natureza, é um ser em harmonia, equilibrado e capaz, física e espiritualmente, de prover tudo quanto é necessário à preservação da sua própria vida e do seu grupo, retirando do meio ambiente somente aquilo que é suficiente. Neste ponto é importante um esclarecimento: se, para Rousseau, a natureza é um dado real, presente, determinante; o estado de natureza é uma hipótese: "um estado que não existe, que talvez nunca tenha existido, que provavelmente jamais existirá, e sobre o qual se tem, contudo, a necessidade de alcançar noções exatas para bem julgar de nosso estado presente" (ROUSSEAU, 1999a, p. 44-5).

Rousseau (1999a) apresenta o estado de natureza como um contraponto ao modo pelo qual os filósofos dele fizeram uso. Almeja verificar a plausibilidade do estado de natureza e quer demonstrar o erro fundamental de seus contemporâneos, que foi o de nunca terem chegado lá (SOARES, 2019). Atribuíram ao estado de natureza características que só passaram a existir na civilização: "falavam do homem selvagem e descreviam o homem civil" (ROUSSEAU, 1999a, p. 52).

Para Rousseau (1999a), o corpo é o instrumento fundamental para o indivíduo no estado de natureza. Ele precisa adequar suas ações, aguçar os sentidos, entender a natureza à sua volta, tomando as decisões mais cabíveis a sua própria preservação e do seu grupo. Não é bom nem mal, porque tais atribuições já constituem princípios morais que só amadurecem com a civilização. A partir daí Rousseau pode afirmar que Hobbes não entendeu o estado de natureza: "ele diz justamente o contrário por ter incluído, inoportunamente, no desejo de 
conservação do homem selvagem a necessidade de satisfazer uma multidão de paixões que são obra da sociedade e que torna as leis necessárias" (ROUSSEAU, 1999a, p. 76).

As desigualdades constituem o ser humano de modo que, por elas e com elas, tornase necessário que a conservação da vida dependa da constituição e da complexidade corporal dos indivíduos. Para Paiva (2016), é um período da humanidade em que as pessoas não são cativas da moral ou escravas da propriedade privada, desfrutando de uma liberdade plena. A civilização leva os indivíduos a criar uma outra forma de viver, na qual as potências corporais passam a figurar em segundo plano, degeneradas.

Trata-se do segundo tipo de desigualdade que, para Rousseau (1999a), só se estabelece a partir do desenvolvimento e complexificação da sociedade civil: a desigualdade moral e política origina todo vício, depravação, privilégio, riqueza e pobreza. Ela está fundada na mais básica das desigualdades, a propriedade privada, nas palavras do filósofo: "o verdadeiro fundador da sociedade civil foi o primeiro que, tendo cercado um terreno, lembrou-se de dizer, isto é meu e encontrou pessoas suficientemente simples para acredita-lo" (ROUSSEAU, 1999a, p. 87, grifos do autor).

As desigualdades naturais dependem das características inerentes aos indivíduos, como sua capacidade de resolver as dificuldades que a natureza lhes impõe. As pessoas são reativas à natureza e felizes (ROUSSEAU, 1999a). O segundo tipo de desigualdade é uma produção da civilização, acompanhada pela complexificação da moral, da instituição da linguagem e do assentamento da noção de propriedade privada (ROUSSEAU, 1999a). No primeiro caso, os indivíduos não possuem controle, no segundo, não só possuem como produzem tais desigualdades. Com a civilização, os seres humanos passam a ser ativos em relação à natureza, construindo um mundo especificamente humano no qual as diferenças naturais deixam de ser decisivas. O progresso da civilização é também o progresso das desigualdades (ROUSSEAU, 1999a).

Mas, como se dá esse progresso? Como essa passagem do selvagem robusto e sadio para o civilizado frágil e depravado se efetiva? Agora é preciso dissertar, ainda que rapidamente, sobre dois pontos centrais em Rousseau: a perfectibilidade e a liberdade. A primeira pode ser entendida como uma faculdade exclusivamente humana, que se constitui como presente dúbio, uma vez que é por ela e com ela que se efetiva o distanciamento em relação à natureza, em direção à civilização. A perfectibilidade é a capacidade humana de aprender e de melhorar-se. É a faculdade que possibilita superar o estado de natureza, mas, ao mesmo tempo, é a causa de todos os males da civilização (NODARI, 2019). 
Rousseau reconhece esse caráter contraditório ao apresentar a qualidade humana de aperfeiçoar-se como aquela a partir da qual desenvolve-se a propriedade privada, a avidez por riquezas, que leva o homem a buscar para si muito mais provisões do que lhe é necessário. A propriedade privada impôs à maioria das pessoas o jugo impiedoso do trabalho: "o trabalho tornou-se necessário e as vastas florestas transformaram-se em campos aprazíveis que se impôs regar com o suor dos homens e nos quais logo se viu a escravidão e a miséria germinarem e crescerem com as colheitas" (ROUSSEAU, 1999a, p. 94).

A evolução da civilização significa, para o genebrino, a marcha em direção à perda da liberdade: da autonomia e da dedicação ao coletivo de que fazia parte, o indivíduo se torna escravo de um sem número de novas necessidades criadas, tornando-se prisioneiro da vaidade e das convenções morais. Ricos ou pobres, são agrilhoados a relações que diluem a liberdade e a originalidade. O resultado é a ambição, o desejo de enriquecimento, a luta por colocar-se acima do outro por pura vaidade e que leva à tendência de os indivíduos prejudicarem-se uns aos outros (ROUSSEAU, 1999a). A política torna-se o instrumento para a manutenção dos interesses dos poderosos e delimitadora da liberdade. Nas palavras do autor:

Tal foi ou deveu ser a origem da sociedade e das leis, que deram novos entraves ao pobre e novas forças ao rico, destruíram irremediavelmente a liberdade natural, fixaram para sempre a lei da propriedade e da desigualdade, fizeram de uma usurpação sagaz um direito irrevogável e, para lucro de alguns ambiciosos, daí por diante sujeitaram todo gênero humano ao trabalho, à servidão e à miséria (ROUSSEAU, 1999a, p. 100).

A política torna-se o campo de batalha de diferentes interesses, institui-se como um sistema no qual os privilégios não são mais de ascendência, mas de posses. $\mathrm{O}$ aparato político se converte em potencializador da desigualdade (ROUSSEAU, 1999c). Além da crítica ao absolutismo, Rousseau é também cético em relação ao novo cenário social que se desenhava: o do Estado burguês. Isto porque o avanço por ele representado não mudava as relações de desigualdade social, uma vez que permanecia aquilo que o genebrino considerava como sendo sua primeira expressão: a propriedade privada. Embora a sociedade tenha mudado, embora tenha havido progresso, ela se mostrava cada vez mais decadente.

Desigualdade natural e desigualdade moral e política só podem ser separadas hipoteticamente, visto estarem presentes em cada indivíduo e em todo o gênero humano. Mas qual é o ponto em que uma passa a determinar a outra? Esse é o questionamento de fundo que Rousseau (1999a) faz e que o leva à conclusão de que a civilização perverteu os seres humanos. $\mathrm{Na}$ medida em que degrada a liberdade e institui a desigualdade social como mal estrutural, a 
civilização perverte também a própria natureza humana. Não só é incapaz, a sociedade civil, de prover a liberdade, como agrilhoa a todos os indivíduos, tornando-os escravos não mais uns dos outros, mas do próprio sistema social criado: "o homem nasce livre, e por toda parte encontrase a ferros. O que se crê senhor dos demais, não deixa de ser mais escravo do que eles" (ROUSSEAU, 1999c, p. 53) ${ }^{2}$.

O progresso da humanidade institui a sociedade civil, mas impõe limitações à liberdade. Não é a "natureza humana" que promove a degradação social, mas o caminho trilhado pela própria civilização. O problema, então, não é da natureza, mas da cultura, das relações estabelecidas pela civilização que tornou artificiais as relações humanas (PAIVA, 2016). Para o genebrino, um outro caminho deve levar os indivíduos a entenderem que é preferível abrir mão da liberdade natural (limitada somente pelas forças e capacidades do indivíduo) em direção à liberdade civil (na qual o indivíduo limita o uso de suas capacidades à vontade geral) (ROUSSEAU, 1999c).

Essa nova direção é a de uma sociedade livre e moral. Rousseau (1999c) quer apresentar um caminho para que, sendo civilizado, o indivíduo possa abrir mão de sua liberdade natural e conquistar a liberdade verdadeira, que só pode existir a partir de um contrato social. $\mathrm{O}$ afastamento em relação à natureza não significa um caminho sem volta, mas, antes, um caminho que precisa ser trilhado de novo, a fim de que os indivíduos desenvolvam uma outra sociedade, uma outra forma de organização social (ROUSSEAU, 1999c). A educação, nesse caso, tem um papel decisivo: "nascemos fracos, precisamos de força; nascemos carentes, precisamos de assistência; nascemos estúpidos, precisamos de juízo. Tudo o que não temos ao nascer e de que precisamos quando grandes nos é dado pela educação" (ROUSSEAU, 1995, p. 8).

\section{Rousseau: Corpo e Educação}

A ideia de que os seres humanos necessitam de um processo formativo não é um conceito novo. Rousseau (1995) o resgata do contratualista inglês John Locke (1986), para quem os indivíduos são melhores ou piores pela educação que recebem. Mas o contexto no qual Rousseau se encontrava oferecia um cenário propício aos projetos educacionais mais

\footnotetext{
${ }^{2}$ No século XIX (em 1807), o filósofo alemão Hegel retomará essa relação entre o que se julga senhor e o que se apresenta como escravo na dialética do senhor e do escravo, na qual demonstra que a consciência de si só se pode efetivar mediatizada por outra consciência (HEGEL, 2008).
}

\begin{tabular}{|l|l|l|l|l|}
\hline Qovista Dialectus & Ano 10 & n. 23 & Maio - Agosto 2021 & p. 307 - 325 \\
\hline
\end{tabular}


progressistas. No século XVIII, a reivindicação por uma educação pública ganhou força e a questão da formação do cidadão livre, emancipado politicamente e apto ao trabalho nos moldes burgueses tornou-se relevante (GADOTTI, 2001). A educação deixa de ser hegemonizada pela Igreja, deslocando-se para a esfera do Estado: "Nessa época desenvolveu-se o esforço da burguesia para estabelecer o controle civil (não religioso) da educação através da instituição do ensino público nacional (GADOTTI, 2001, p. 89. Grifos do autor).

Manacorda (2000) explica que o formato escolástico, baseado nos estudos livrescos, extremamente elitizado, disciplinado e disciplinador pelos castigos físicos, não era mais suficiente e que novas formas para a educação se impunham. Rousseau (1995; 1999a) está imerso nessa discussão. Suas ideias sobre a sociedade, a civilização, o contrato social, a infância, o corpo e a formação do novo homem para a nova sociedade expressam uma disputa política pela hegemonia entre a burguesia e a aristocracia, expressa também uma disputa pela educação. Para o genebrino, a educação escolástica não instrui para as transformações em curso. É preciso capacitar os jovens a adaptarem-se ao mundo novo, encaminhando sujeitos familiarizados com a natureza, mas com conhecimentos científicos para atuar sobre esse mundo: ele quer o natural junto com o social, e essa é a inovação em relação à formação humana que Rousseau traz, seguindo o modelo muito difundido na época: o Robinson Crusoé, de Daniel Defoe (1660 - 1731).

Essas ideias agradavam a burguesia e, a fim de elaborar esse plano de ação para a educação, seria necessária uma retomada dos ideais antigos como guias para a nova sociedade pretendida. É assim que os iluministas resgatam o pensamento clássico dos antigos gregos e romanos, demonstrando a necessidade da razão para vencer o obscurantismo medieval e é assim que procede Rousseau em relação à necessidade de uma vida mais simples, mais natural, diferente daquela que leva à degradação do ser humano. No comentário de Ponce:

\footnotetext{
Quando da decadência do mundo antigo, foram os estoicos que proclamaram a urgência de uma vida mais simples; quando da decadência do feudalismo, foram os renascentistas que, em nome de uma "volta ao antigo", impuseram um paganismo da carne e da beleza; e agora, quando a monarquia, levantada sobre as ruínas do feudalismo, sentia que a sua antiga aliada, a burguesia, ia crescendo em ambição e ousadia, surge Rousseau, para proclamar, com entusiasmo ardente, o Evangelho da Natureza (PONCE, 2000, P. 128).
}

O evangelho da natureza não significa abandono da civilização e retorno a um estado natural hipotético e primitivo, mas uma reformulação, uma reorganização e uma reconstrução da civilização que depende somente das forças e do empenho dos próprios seres 
humanos (NODARI, 2019). Nesse "abandono" civilizado da civilização, a educação ocupa posição destacada por ser um instrumento privilegiado para mudar a sociedade a partir da formação de indivíduos que, a exemplo dos antigos, incorporem as melhores qualidades do corpo e do espírito: "esse é o meio de um dia obter o que acreditamos ser incompatível e o que quase todos os grandes homens reuniram, a força do corpo e a força da alma, a razão de um sábio e o vigor de um atleta" (ROUSSEAU, 1995, p. 132).

Quanto à educação do corpo, Rousseau tampouco é um inovador do tema. Ele procura nos antigos gregos e romanos os fundamentos da preparação do corpo pelos exercícios; nas descobertas realizadas no novo mundo, a constituição corporal do homem primitivo (não civilizado); em pensadores como Montaigne e Locke, os elementos do fortalecimento da alma pela via do corpo sadio e capaz de enfrentar as intempéries da vida como indivíduo livre. A inovação de Rousseau está em sustentar suas ideias na premissa de que o indivíduo em estado de natureza precisava manter o corpo plenamente ativo para ser capaz de defender sua existência (ROUSSEAU, 1995). O próprio modo de viver exigia um indivíduo ativo e, quando o corpo não fosse mais capaz de garantir a sobrevivência, pereceria. Para Rousseau, o corpo é o instrumento do indivíduo primitivo:

Sendo o corpo o único instrumento que o homem selvagem conhece, é por ele empregado de diversos modos, de que são incapazes, dada a falta de exercícios, nossos corpos, e foi nossa indústria que nos privou da força e da agilidade que a necessidade obrigou o selvagem a adquirir (ROUSSEAU, 1995, p. 59).

Alerta-nos Vigarello (2008) que não se trata, contudo, do exercício tal como o concebemos nos dias atuais, não há em Rousseau uma classificação dos exercícios, não há agrupamento nem há um sistema, mas uma proposta que leva em conta as demandas do próprio corpo por movimento e pelo fortalecimento dos músculos: "o projeto revoluciona de um lado ao outro a visão clássica do exercício, dando ao músculo uma força até então ignorada: um recurso preciso e orientado" (VIGARELLO, 2008, p. 385).

Como a degradação do corpo exprime a degradação moral e política da civilização, a educação deve atuar acompanhando o desenvolvimento corporal do modo mais natural possível, mas também orientando a organização da conduta desse corpo, observando as leis naturais, bem como as demandas de uma vida civilizada equilibrada. Acima de tudo, a organização da conduta deve prezar pela liberdade. Em Rousseau (1995), a educação do corpo está entrelaçada com a política, com a ciência e com a formação moral que supere aquela do antigo regime e, para tratar disso, retoma o estado de natureza: "não constituem, pois, para esses 
primeiros homens, nem tão grande mal, nem, sobretudo, tão grande obstáculo à sua preservação a nudez, a falta de moradia e a privação de todas as inutilidades que consideramos tão necessárias" (ROUSSEAU, 1999a, p. 63).

A educação é uma instituição da sociedade e, portanto, tem uma função a cumprir. Para a formação do novo homem, Rousseau (1995) pensa numa instituição que retire o indivíduo do estado de natureza, mas que lhe garanta aquela liberdade civil preconizada pelo contrato social, que substitui a existência absoluta pela relativa e enreda o indivíduo em seu coletivo "de sorte que cada particular não se julgue mais como tal, e sim como uma parte da unidade, e só seja perceptível no todo" (ROUSSEAU, 1995, p. 11).

O desenvolvimento desse sujeito deve iniciar desde muito cedo, posto que as mudanças exigidas sejam muitas e profundas, devendo a educação ser como uma estratégia de construção dos hábitos mais desejáveis aos novos modos de vida. Nessa direção, "a saúde e o vigor dos corpos, bem como a formação moral, eram dois objectivos (sic) complementares, definidos a partir de um conhecimento mais perfeito da realidade" (CRESPO, 1990, P. 464).

À criança devem ser encaminhados os esforços de reorganização dos hábitos, de fortalecimento do corpo, de capacitação para os novos tempos. O genebrino apresenta um entendimento da infância essencialmente diferente daquela que predomina em seu tempo: o de que haja uma particularidade nessa fase da vida. A criança tem um modo de pensar e de perceber próprio e diferente do adulto (POSTMAN, 1999; LUZURIAGA, 1979). Rousseau (1995) não só distingue a infância da idade adulta, como cobra mais atenção e conhecimento da natureza infantil e dos processos formativos mais adequados. "A infância tem maneiras de ver, de pensar e de sentir que lhe são próprias; nada é menos sensato do que querer substituir essas maneiras pelas nossas" (ROUSSEAU, 1995, p. 86).

Recomenda ainda não vetar aos pequeninos o direito de movimentar-se conforme sua vontade, pois é uma condição necessária à vida: "todos os seus movimentos são necessidades de sua constituição, que procura fortalecer-se" (ROUSSEAU, 1995, p. 79). É já nos primeiros meses de vida que se inicia a educação do corpo. Os obstáculos presentes no entorno da criança formam os primeiros desafios naturais e, por isso, o corpo deve ficar livre de faixas e vestimentas que impeçam ou dificultem o movimento: "Quando começar a ficar mais forte, deixai-a engatinhar pelo quarto, deixai que a criança se desenvolva e estique as perninhas e os bracinhos e vereis que ela se fortalecerá a cada dia" (ROUSSEAU, 1995, p. 43).

Sugere ainda o genebrino que se compare a criança livre de faixas que prendem o corpo com outra, enfaixada e presa a um berço, para que se verifique a evolução de cada uma 
delas. O primeiro objeto da educação do cidadão do futuro é o corpo do bebê, que percebe o ambiente pela visão ainda imprecisa e pela audição ainda caótica, mas também, quando livre de óbices ao movimento, pelo tato, pelo olfato. $\mathrm{O}$ mediador dessa experiência da criança dever ser a própria necessidade de movimento, desde que resguardada, pelo adulto, a segurança: "Eis, portanto, uma nova razão, muito importante, para deixar os corpos e os membros das crianças absolutamente livres, com a única precaução de afastá-los dos perigos de queda e de tirar de suas mãos tudo que possa feri-las" (ROUSSEAU, 1995, p. 55).

Para a criança, a descoberta do entorno, das diferentes texturas, das distâncias, constitui o primeiro movimento em direção ao melhor conhecimento de suas próprias forças. $\mathrm{O}$ corpo começa a ser educado, ou seja, começa a se relacionar com o mundo de um modo social, e não mais puramente instintivo, como no indivíduo primitivo: “é apenas pelo movimento que aprendemos que existem coisas que não são nós, e é apenas por nosso próprio movimento que adquirimos a ideia da extensão" (ROUSSEAU, 1995, p. 49).

A criança é aprendiz da experiência e, nisso, está ligada ao estado de natureza, mas é acompanhada por um adulto, e, nisso, suas experiências já passam a ser culturais, civilizadas. Até por isso, ao adulto cabe estudar a natureza, observa-la, entende-la e segui-la a fim de resguardar a integridade da criança, bem como dirigir suas ações dando a ela mais liberdade e menos domínio, levando-a a fazer mais por si mesma, exigindo menos dos outros: “Assim, acostumando-se cedo a limitar seus desejos às suas forças, pouco sentirão a privação do que não estiver em seu poder" (ROUSSEAU, 1995, p. 55).

Embora a criança seja obviamente capaz de aprender, isso indica que ainda não conhece a maior parte das coisas e, por isso, precisa da presença do adulto. Mas essa presença deve ser respeitosa com os ritmos da natureza e com os interesses da própria criança, que aprende antes mesmo de ter consciência disso. Os estímulos, o afeto, o hábito e os limites expostos à criança não devem intimida-la, mas desenvolver a coragem, sem, com isso, impor o modo adulto de entender o mundo (ROUSSEAU, 1995).

Boto (2011) observa que, nesse movimento, Rousseau procura recuperar na criança aquelas características do estado natural como estratégia para a formação do cidadão: "Tratase de buscar a origem. Do mesmo modo, a criança que Rousseau via em seu tempo teria transfigurada sua original identidade pelo efeito da civilização. Havia de se perscrutar o que tinha sobrado da primeira infância natural” (BOTO, 2011, p. 162).

Sendo impossível paralisar o progresso humano na infância, Rousseau (1995) aponta para a formação do indivíduo como possibilidade de redenção da sociedade. Pela 
educação capaz de preservar a essência do estado de natureza se pode formar um indivíduo civilizado, mas não degradado, capaz de mover-se na sociedade sem ser por ela pervertido. É o "homem total", que não é um profissional liberal em específico, mas, de tudo que se espera do indivíduo livre de sua época, “ele será capaz de ser, se preciso, tão bem quanto qualquer outro; e, ainda que a fortuna o faça mudar de lugar, ele sempre estará no seu" (ROUSSEAU, 1995, p. 14).

Como encaminhar tal formação? A estratégia é ter a natureza como guia para a educação. Manter o corpo íntegro pelo exercício e encaminhar somente os conhecimentos úteis para a vida. Assim, na medida em que cresce, a criança tem liberdade para escolher o que quer, e isso se evidencia em sua curiosidade, em seu interesse e na capacidade do adulto em guiarlhe os passos. "É então que ela poderá entregar-se aos exercícios do corpo que a idade requer, sem embrutecer o espírito" (ROUSSEAU, 1995, p. 133).

A preocupação de Rousseau (1995) com o corpo diz respeito às demandas dos tempos vividos pelo autor e é entrelaçada com sua concepção de mundo. A nova sociedade, tanto aquela que se ia constituindo como aquela idealizada por Rousseau, necessitava de indivíduos emancipados do obscurantismo do passado e formados, tanto física quanto intelectualmente, para transformar o mundo.

A correção de caminho para a civilização passava necessariamente pela educação e pela mudança na concepção de infância. Se o desenvolvimento da civilização causou a decadência dos indivíduos, urge então repensar o modo como essa sociedade está organizada. Isso requer um indivíduo diferente daquele considerado ideal para o antigo regime, e, portanto, um processo formativo que eduque para um novo mundo. Não se trata, para ele, de educar a criança para a sociedade, mas de preparar novos indivíduos para uma nova sociedade (BOTO, 2011).

\section{Considerações Finais}

A partir das reflexões apresentadas ao logo do texto, entende-se que Rousseau se insere no pensamento de seu tempo histórico ao procurar no hipotético estado de natureza os fundamentos daquilo que dá substância à humanidade, mas é também um crítico desse mesmo pensamento quando não atribui aos primórdios da humanidade os defeitos e vícios do presente, que não são naturais, mas produtos de um determinado tipo de progresso da civilização. Para Rousseau (1995) não é possível encaminhar o conhecimento científico que não se aplique à 
própria vida cotidiana e não é possível pensar a educação da criança sem considerar as demandas e particularidades da infância.

Esse posicionamento do genebrino impacta significativamente todo pensamento pedagógico desde a sua época até os dias atuais (BOTO, 2011). Exemplo dessa influência é a Escola Nova, o construtivismo piagetiano e as proposições de educação ao longo da vida. Entretanto, não se deve reduzir a influência rousseauniana a propostas educacionais de cunho empiricista unicamente, a própria concepção de infância inaugurada e defendida por ele está presente em todas as proposições sobre a educação nos dias atuais.

Embora seja diferente do adulto, é na criança que se deve formar o corpo forte, resistente, gracioso e livre. Estudar a infância, para Rousseau (1995), é condição para se compreender o adulto. Dois pontos devem ser destacados aqui: primeiro, Rousseau institui a infância como um período particular, especial para o desenvolvimento do ser humano. Ao fazer isso, aponta para a necessidade de que esse período seja melhor compreendido, a fim de que a educação contemple melhor as necessidades humanas. A infância demanda que haja um cuidado especial e específico com o corpo que se insere no mundo.

Em segundo lugar, o desenvolvimento do indivíduo replica o desenvolvimento do gênero. A infância corresponde ao estado de natureza que, na sociedade criticada por Rousseau, seria deteriorada conforme se tornasse mais civilizada. Permanece no indivíduo civilizado vestígios do indivíduo natural, e, embora degradados, são nesses vestígios que se encontra a possibilidade de redenção da humanidade. A educação, ao resgatar a relação do ser humano com a natureza, ao retomar a centralidade do corpo, torna-se um instrumento de transformação social. Por um lado, corpo e espírito, embora diferentes, estão integrados e, por outro, política, educação e sociedade são imbricados em toda a obra rousseauniana (BOTO, 2011; MANACORDA, 2000).

Por isso a educação do corpo é fundamental: se a infância reflete o desenvolvimento humano desde o estado de natureza, é esse o momento de educar o indivíduo de modo a preservar os bons instintos, a força e a saúde do corpo, a interação com a natureza e, pela razão, instituir uma visão de mundo que não separe de forma hostil o natural e o social, mas que se tornem de fato complementares e, então, o indivíduo será pleno. $\mathrm{O}$ resgate da natureza no âmbito da sociedade é o resgate da própria civilização. Para Rousseau (1999c), o aprimoramento do indivíduo só se completa na medida em que seja extensão da comunidade e só então haveria igualdade social efetiva. Trata-se de uma busca coletiva que garante a melhoria de cada indivíduo e torna possível construir uma sociedade na qual a condição natural não seja 
subtraída pela civilização e pelos privilégios, mas que seja o guia da própria sociedade para a superação das desigualdades sociais.

Pelo contrato social se supera a desigualdade natural em direção à igualdade moral e política (ROUSSEAU, 1999c). A primeira é compensada pela sociedade, que deverá prover a igualdade por convenção e direito (ROUSSEAU, 1999c). Esse é o cenário idealizado por Rousseau e no qual se insere a educação como instrumento privilegiado, pois é o único capaz de transformar os indivíduos. Tendo sido levado à corrupção, degenerescência e degradação, é preciso resgatar nos seres humanos os melhores instintos e isso é uma missão a ser assumida por todo gênero humano (NODARI, 2019). O pacto social deve preservar tanto os avanços civilizatórios quanto a liberdade e, se eventualmente se perde aquela liberdade individual do estado de natureza, se ganha com as possibilidades que a nova sociedade baseada no contrato social pode proporcionar: a liberdade social, política e moral (ROUSSEAU, 1999c).

Pela necessidade o corpo forte, ágil e saudável do ser humano em estado de natureza é forjado e, por degradação causada pela civilização, o corpo torna-se incapaz de efetivar-se como instrumento de autorrealização da espécie humana. Talvez seja esta uma das importantes lições deixadas por Rousseau para os tempos atuais, repletos de caminhos que tornam a relação com a natureza estranha aos indivíduos. Na civilização que coloca em risco a existência de toda a espécie humana por seu desrespeito à natureza, resgatar as ideias de Rousseau sobre uma sociedade equilibrada, ainda que idealizada, pode ser um alento importante. Ao reivindicar o corpo no centro da educação, como instrumento para a experimentação e para a relação harmônica com a natureza, o genebrino faz do seu "evangelho da natureza" (PONCE, 2000) uma forma de encontrar a relação mais harmoniosa entre a civilização e o mundo natural.

Considerando que a educação começa com o nascimento, Rousseau (1995) apresenta uma concepção a partir da qual o desenvolvimento natural do corpo deva ser respeitado no processo civilizatório da criança. Entanto, ela não se educa sozinha, é preciso a mediação do adulto e, nisso, natureza e cultura se encontram. A própria decisão de se retirar a criança do ambiente social para inseri-la na natureza é, desde o princípio, cultural, histórica, politicamente comprometida com os ideais de liberdade defendidos pelo genebrino. Rousseau quer um indivíduo capaz de se movimentar na sociedade com desenvoltura e de modo a criar um mundo novo: não nega a natureza, não nega a civilização, mas se propõe construir uma civilização mais livre, mais fraterna e mais igual. O corpo humano é o centro dessa formação, posto que seja o fundamento da própria existência. "Só uma longa experiência pode ensinar- 
nos a tirar partido de nós próprios, e esta experiência é o verdadeiro estudo em que nunca é cedo demais para nos aplicarmos" (ROUSSEAU, 1995, p. 175). 


\section{Referências}

ARIÈS, Phillippe. História Social da Criança e da Família. Rio de Janeiro: LTC - Livros Técnicos e Científicos Editora; 1981.

BOTO, Carlota Josefina Malta Cardozo dos Reis. Instrução Pública e Projeto Civilizador: o século XVIII como intérprete da ciência, da infância e da escola. 2011. 379 p. Tese (Livre Docência) - Faculdade de Educação, Universidade de São Paulo, São Paulo, 2011. Disponível em: $\quad$ http://www.teses.usp.br/teses/disponiveis/livredocencia/48/tde-12092011-152740/ Acesso em: 01/07/2020.

CRESPO, Jorge. A História do Corpo. Lisboa: Difel Difusão Editorial; Rio de Janeiro: Editora Bertrand Brasil, 1990.

ENGELS. Friedrich. Anti-Dühring: a revolução da ciência segundo o senhor Eugen Dühring. Trad. Nélio Schneider. $1^{\mathrm{a}}$ Ed. São Paulo: Boitempo, 2015.

GADOTTI, Moacir, História das Ideias Pedagógicas. 8ª Ed. São Paulo: Editora Ática; 2001.

HEGEL, G. W. F. Fenomenologia do Espírito. Tradução de Paulo Meneses. Petrópolis/RJ: Vozes; Bragança Paulista: Editora Universitária São Francisco; 2008.

HOBSBAWN. Eric J. A Era das Revoluções (1789-1848). São Paulo: Paz e Terra; 2011.

LOCKE, John. Pensamientos Sobre la Educación. Madrid: Ediciones AKAL; 1986.

LUZURIAGA, Lorenzo. História da Educação e da Pedagogia. São Paulo: Companhia Editora Nacional; 1979.

MANACORDA, Mário Alighiero. História da Educação: da antiguidade aos nossos dias. São Paulo: Cortez; 2000.

NODARI, Paulo Cesar. Perfectibilidade, Liberdade e Educação em Rousseau. In: Revista Dialectus. Fortaleza/CE, Ano 8, No 15, ago/dez 2019, p. 253-267.

PAIVA, Wilson Alves de. Progresso e Depravação: a cultura como remédio. In: Kriterion, Belo Horizonte, nº 134, Ago./2016, p. 421-440.

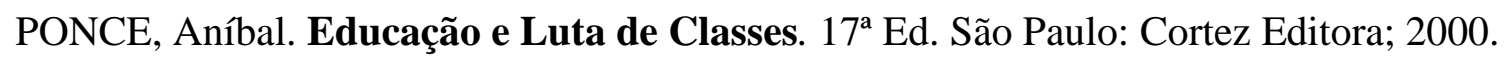

POSTMAN, Neil. O Desaparecimento da Infância. Rio de Janeiro: Graphia; 1999.

ROUSSEAU, Jean-Jacques. Emílio ou da Educação. São Paulo: Martins Fontes; 1995.

ROUSSEAU, Jean-Jacques. Discurso sobre a Origem e os Fundamentos da Desigualdade entre os Homens. Tradução de Lourdes Santos Machado. Introduções e notas de Paul Arbousse-Bastide e Lourival Gomes Machado. São Paulo: Nova Cultural, 1999a. (Coleção Os Pensadores; Vol. II).

ROUSSEAU, Jean-Jacques. Discurso sobre as Ciências e as Artes. Tradução de Lourdes Santos Machado. Introduções e notas de Paul Arbousse-Bastide e Lourival Gomes Machado. São Paulo: Nova Cultural, 1999b. (Coleção Os Pensadores; Vol. II).

ROUSSEAU, Jean-Jacques. Do Contrato Social. Tradução de Lourdes Santos Machado. Introduções e notas de Paul Arbousse-Bastide e Lourival Gomes Machado. São. Paulo: Nova Cultural, 1999c. (Coleção Os Pensadores; Vol. I). 
SOARES, Telmir de Souza. Sobre a Hipótese do Estado de Natureza e sua Relação com a Natureza em Rousseau: pressupostos e corolários. IN: Revista Dialectus. Fortaleza/CE, Ano 8, no 15, ago/dez 2019, p. 304-327.

VIGARELLO, Georges. Exercitar-se, Jogar. IN: CORBIN, Alain; COURTINE, JeanJacques; VIGARELlO, Georges. História do Corpo: da Renascença às Luzes. $2^{\mathrm{a}} \mathrm{Ed}$. Petrópolis/RJ; Editora Vozes: 2008, p. 303-399. 